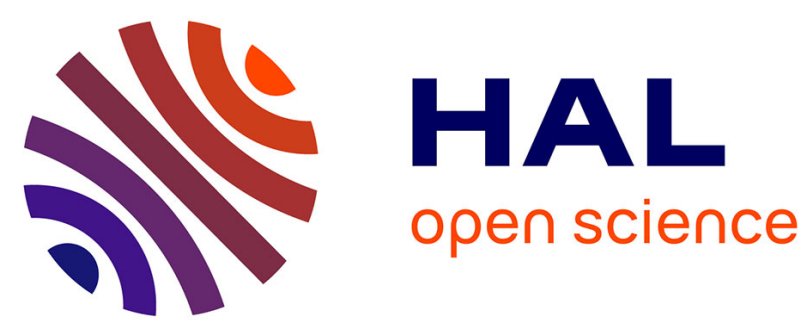

\title{
Does watching Han Solo or C-3PO similarly influence our language processing?
}

Sophie-Anne Beauprez, Christel Bidet-Ildei, Kazuo Hiraki

\section{To cite this version:}

Sophie-Anne Beauprez, Christel Bidet-Ildei, Kazuo Hiraki. Does watching Han Solo or C-3PO similarly influence our language processing?. Psychological Research, 2019, 10.1007/s00426-019-01169-3 . hal-02088610

\section{HAL Id: hal-02088610 https://hal.science/hal-02088610}

Submitted on 3 Apr 2019

HAL is a multi-disciplinary open access archive for the deposit and dissemination of scientific research documents, whether they are published or not. The documents may come from teaching and research institutions in France or abroad, or from public or private research centers.
L'archive ouverte pluridisciplinaire HAL, est destinée au dépôt et à la diffusion de documents scientifiques de niveau recherche, publiés ou non, émanant des établissements d'enseignement et de recherche français ou étrangers, des laboratoires publics ou privés. 
Does watching Han Solo or C-3PO similarly influence our language processing? Beauprez Sophie-Anne ${ }^{1}$, Bidet-Ildei Christel $^{1} \&$ Hiraki Kazuo $^{2}$

${ }^{1}$ Université de Poitiers; Université de Tours; Centre National de la Recherche Scientifique; Centre de Recherches sur la Cognition et l'Apprentissage (UMR 7295), Poitiers, France

${ }^{2}$ Department of Systems Science; Graduate School of Arts and Sciences; The University of Tokyo, Tokyo, Japan

Corresponding Author: Christel Bidet-Ildei

Mailing Address: christel.bidet@univ-poitiers.fr

Bâtiment A5 (CeRCA)

5 rue Théodore Lefebvre - TSA 21103

86073 Poitiers cedex 9

Tel.: 33 (0)5 49454697 


\section{Abstract:}

Several studies have demonstrated that perceiving an action influences the subsequent processing of action verbs. However, which characteristics of the perceived action are truly determinant to enable this influence are still unknown. The current study investigated the role of the agent executing an action in this action-language relationship. Participants performed a semantic decision task after seeing a video of a human or a robot performing an action. The results of the first study showed that perceiving a human being executing an action as well as perceiving a robot facilitates subsequent language processing suggesting that the humanness ${ }^{1}$ of the agent is not crucial in the link between action and language. However, this experiment was conducted with Japanese people who are very familiar with robots; thus, an alternative explanation could be that it is the unfamiliarity with the agent that could perturb the actionlanguage relationship. To assess this hypothesis, we carried out two additional experiments with French participants. The results of the second study showed that, unlike the observation of a human agent, the observation of a robot did not influence language processing. Finally, the results of the third study showed that, after a familiarization phase, French participants too were influenced by the observation of a robot. Overall, the outcomes of these studies indicate that, more than the humanness of the agent, it is the familiarity we have with this agent that is crucial in the action-language relationship.

Keywords: humanoid robot, action perception, language, appearance, familiarity

\footnotetext{
${ }^{1}$ The term "humanness" is used as meaning "belonging to human race" and not to refer to a personal quality
} 


\section{Introduction}

The embodiment theory postulates that all cognitive functions are related to sensorimotor experiences (Barsalou, 1999). In the present study, we propose to focus on the link between action and language.

1. A relationship between action and language processing

A growing body of literature exists on the topic of the relationship between action and language. Numerous studies have demonstrated that action execution can be influenced by language (see for examples, Aravena et al., 2012; Boulenger et al., 2006; Glenberg \& Kaschak, 2002; Lindemann, Stenneken, van Schie, \& Bekkering, 2006). This link has been demonstrated at a behavioral level. For example, Zwaan and his colleagues (2006) asked their participants to answer a question by turning a knob in a specific direction. Participants were quicker to judge a sentence when the manual response to this sentence was in the same rotational direction as the manual action described by the sentence (for example, turning the knob to the right for a sentence implying a clockwise rotation like "Jane started the car" or turning the knob to the left for a sentence implying a counterclockwise rotation like "Liza opened the pickle jar"). These results suggest that the production of an action and language processing could be based on common processing and use similar brain correlates. To test this assumption, numerous brain studies were carried out. These studies demonstrated the involvement of brain motor areas using functional magnetic resonance imaging (Aziz-Zadeh \& Damasio, 2008; Hauk, Johnsrude, \& Pulvermüller, 2004), magnetoencephalography (Klepp et al., 2014), electroencephalography (Mollo, Pulvermüller, \& Hauk, 2016) or transcranial magnetic stimulation (Kuipers, van koningsbruggen, \& Thierry, 2013). Altogether, these studies showed that the part of the body involved when someone performs actions is also activated when this person processes language describing these actions. 
Interestingly, researchers also demonstrated that this action-language relationship is not restricted to action execution but also occurred when an action is only observed. So, some studies demonstrated that perceiving an action can influence language processing (Beauprez \& Bidet-Ildei, 2017; Liepelt, Dolk, \& Prinz, 2012). Studies by Beauprez and Bidet-Ildei (2017) and Liepelt, Dolk and Prinz (2012) showed that seeing an action enables the participants to answer faster when a verb corresponds to this action.

2. A role of the characteristics of the action?

The study of the action-language relationship involving action perception has the advantage of offering researchers the opportunity to modulate several aspects of the action, which could not be possible when using an action execution paradigm. Thereby, using action observation allows researchers gain knowledge from questions that remain unsolved on the action-language relationship. In particular, it is possible to understand how and which action properties can influence semantic activation during word processing. It can be assumed that the influence of action observation on language is automatic and that as soon as an action is perceived the associated semantic representation is activated (Pulvermüller, 2005). However, recent studies considering these action properties indicate that it is not always the case (Beauprez \& Bidet-Ildei, 2018; Beauprez, Toussaint \& Bidet-Ildei, 2018).

For example, when the context of an action was modified, the influence of action observation on action-verbs processing disappeared (Beauprez, Toussaint \& Bidet-Ildei, 2018).

Indeed, the context in which an action is produced is critical since it provides much information to the understanding of this action (such as the intention of the actor, for example, see Iacoboni et al. 2005). Thus, actions are not perceived in isolation but are rather embedded with objects, actors, and the relationships among them. Indeed, context provides information 
concerning both the environment in which the action is performed and the agent performing the action. In a previous study (Beauprez, Toussaint, \& Bidet-Ildei, 2018), we decided to examine the role of context in the action-relationship by focusing on the environment. In this study, participants observed a picture depicting an action performed in a usual ("to water a plant") or unusual context ("to water a computer") before performing a language decision task. After seeing a usual picture, participants were quicker to judge a congruent action verb ("to water") compared to an incongruent action verb ("to eat"). However, when the context was unusual, no differences were observed between congruent and incongruent verbs. The results indicate that the influence of action observation on language processing is dependent on the context where an action is produced. The question is now to explore the role of the agent performing the action. In particular, we propose to focus on the humanness of the agent. Is language influenced when observing a non-human agent instead of a human agent?

This characteristic is particularly interesting because the crosstalk between action and language may be supported by a mechanism of motor resonance (Zwaan \& Taylor, 2006), involving the activation of sensorimotor representations common to action perception/execution and language processing. The idea is that understanding an action involves an internal simulation of the perceived action (Rizzolatti, Fogassi, \& Gallese, 2001) and that the closer the observed action is to the motor repertoire of the observer, the stronger the resonance should be (Calvo-Merino, Glaser, Grèzes, Passingham, \& Haggard, 2005). Following this logic, we can assume that perceiving another human would lead to more resonance than perceiving a non-human agent.

3. Motor resonance and perceiving robots

In our study, to compare a human and a non-human agent, we used a humanoid robot because we can modify them (appearance, size, kinematic, etc.) more strictly and more easily 
than real humans. So, robots represent a relevant tool to improve understanding of our cognition and how we interact with other human beings. Many studies have investigated the mechanisms sustaining the perception of robot action. However, the literature contains contradictory results.

Some authors have reported that motor resonance appears when perceiving robots (e.g., Gazzola, Rizzolatti, Wicker, \& Keysers, 2007a; Press, Bird, Flach, \& Heyes, 2005). Press, Gillmeister and Heyes (2006) demonstrated, for example, a similar priming effect of robotic and human hands. Moreover, using fMRI, Gazzola and her colleagues (2007a) demonstrated that the mirror neuron system was strongly activated by the sight of both human and robotic action. In the same vein, it has been demonstrated that perceiving robotic and human actions produced equivalent mu suppression ${ }^{2}$; in other words, human and robotic agents produced similar activation of the mirror neuron system (Oberman, McCleery, Ramachandran, \& Pineda, 2007). This mirror neuron system is assumed to play a key role in the relationship between the sensorimotor system and language processing by mediating the mapping of observed actions onto one's own motor repertoire (Aziz-Zadeh, Wilson, Rizzolatti, \& Iacoboni, 2006; Giacomo Rizzolatti \& Craighero, 2004). Thus, if the observation of a robot leads to the activation of the mirror neuron system, these results could indicate that the action-language relationship should be found not only when observing a human being but also when observing robotic agents.

In contrast, other studies have obtained opposite results (e.g., Matsuda, Hiraki, \& Ishiguro, 2015; Tai et al., 2004, Kilner et al. 2013). In their EEG study, Matsuda, Hiraki and Ishiguro (2015) found that human actions evoked significant mu suppression whereas robotic actions did not. Another example is a positron emission tomography study (Tai, Scherfler, Brooks, Sawamoto, \& Castiello, 2004) reporting that the mirror neuron system was activated

\footnotetext{
${ }^{2} \mathrm{Mu}$ is a range of electroencephalography oscillations $(8-13 \mathrm{~Hz})$. Its suppression is considered to reflect mirror neuron system activity
} 
when participants observed a grasping action performed by a human but was not when the same action was performed by a robot. Thus, when perceiving actions performed by a robot, it would be more difficult to activate a motor simulation. Ranzini, Borghi and Nicoletti (2011) provided evidence reinforcing this idea. A compatibility effect was obtained between hand posture (precision or power) and line width (thin or thick), reflecting that motor simulation occurred (the attention of the participant is directed where the hand posture is congruent with the line width). Interestingly, this effect was larger for a biological hand than for a nonbiological hand. Altogether, these studies suggest a higher motor resonance for humans than for robots (see also Anelli et al. 2014).

It has been proposed that the differences between these two kinds of studies (motor resonance with robots vs no motor resonance with robots) could be explained by experimental design differences. Indeed, these studies used different kinds of robots (different levels of anthropomorphism, kinematic similarities with humans, etc.), presented either the entire body of the robots or only parts of them (for example, only the arm) and/or had different experimental instructions. All these parameters could have significant effects on the brain structures involved in the cognitive tasks of these studies (for more information on this subject, see Chaminade and Cheng, 2009).

More precisely, to explain these discrepancies, it has been suggested that, if the task does not impose focusing the attention on the goal of an action, motor resonance could be automatic for human actions, whereas robotic stimuli would not be processed automatically because the participants had no existing sensorimotor representation of the robot's action. Regarding these results, we could assume that the action-language relation should only be found when observing a human being and that observing a robot performing an action would not influence subsequent processing of language. 


\section{The present study}

The aim of the present study was to assess how the action-language relationship would be influenced when perceiving a robot or a human being performing an action. To do so, we compared the priming effect induced by action perception on a semantic decision task. In accordance with previous studies, we hypothesized that the humanness of the agent is an important characteristic of an action. On the one hand, when we perceive a human being performing an action, the mirror neuron system and the sensorimotor representations linked to the perceived action would be activated. Since these representations are shared by language, its processing should be facilitated. On the other hand, when we perceive a robot performing an action, the mirror neuron system and sensorimotor representations would activate less or not at all. In this situation, language would not be influenced. In summary, we hypothesized that perceiving the action of a human agent would facilitate action verb processing, whereas perceiving the action of a non-human (robotic) agent would not (see Fig. 1 for a schematic representation of our hypotheses).

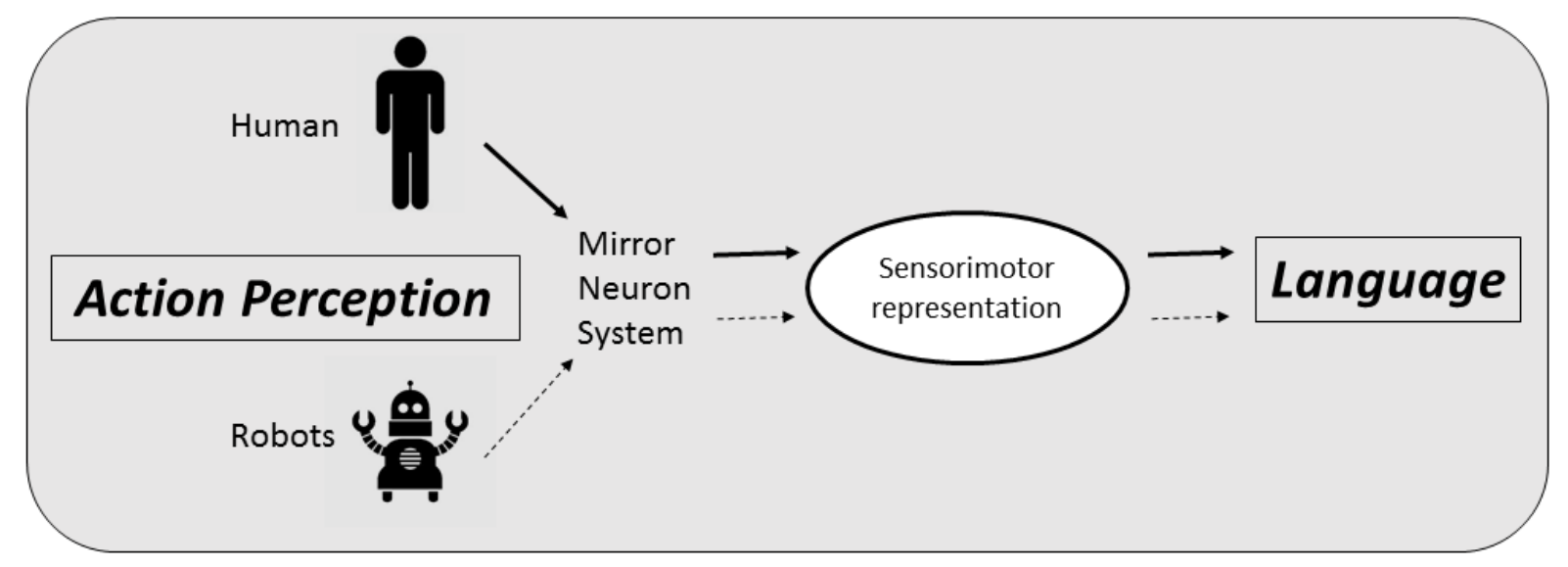

Figure 1. Schematic representation of the hypotheses. Solid lines represent an activation, and dashed lines represent less or no activation. Perceiving a robot and a human being should influence language processing differently. The perception of the human action would activate the representation of this action, which in turn facilitates the processing of the 
verb describing this action, whereas the perception of the robotic action would activate this representation less or not at all.

\section{Experiment 1}

\section{Method}

\subsection{Participants}

Eighteen Japanese university students $(\mathrm{M}=19$-year-old, $\mathrm{SD}=2.01 ; 11$ male, 18 righthanded) participated in this experiment. The sample size was calculated using $G^{*}$ Power 3.0.10 (Faul, Erdfelder, Lang, \& Buchner, 2007). The experiment was based on a repeated measures ANOVA design from the results obtained in a pilot study (Cohen's d value $=0.84$, correlations between repeated measures $=0.5$ ). Statistical significance was set at $p<0.05$ and power at .90. All participants had normal or corrected-to-normal vision, no history of motor, perceptual or neurological disorders, and Japanese as their mother tongue. Moreover, all participants provided their written informed consent prior to their inclusion in the experiment. They were also unaware of the purpose of the study.

\subsection{Prime and Stimuli}

The prime was a video of a human being or a robot performing an action. The videos were in color, muted, and lasted $3000 \mathrm{~ms}$ on average. Sixteen different actions were used (see appendix A. for the list of actions). Each action was performed both by a human actor and a humanoid robot (Nao, the robot from SoftBank Robotics https://www.ald.softbankrobotics.com; see appendix B for examples of frame).

The stimuli were 32 verbs. Half of them were "action verbs" corresponding to the priming action, and the other half were "non-action verbs" (e.g., "think" or "dream"), namely, 
verbs that do not imply movement of the body. The verbs were presented in the neutral form and written with hiragana (see appendix A for the list of verbs).

\subsection{Procedure}

For each participant, the experimental session included 192 trials $(2 \times 16 \times 2 \times 3): 2$ presentations of the 16 actions performed by 2 types of agent (human and robot) that were followed by a verb (congruent action verbs, incongruent actions verbs or non-action verbs).

The presentation order of the trials was randomized across participants. Each trial involved the following procedure (see Fig. 2): a fixation cross appeared for $500 \mathrm{~ms}$ then the prime video was displayed (3000 ms). Finally, following another fixation cross $(500 \mathrm{~ms})$, the stimulus (a verb) appeared and remained on the screen until the participant entered a response. This verb could be an action verb congruent with the prime (for example, seeing the video depicting the action of cleaning before reading the word "clean"), an incongruent action verb (for example, seeing the video depicting the action of cleaning before reading the word "take") or a non-action verb (for example, seeing the video depicting the action of cleaning before reading the word "wish"). The participant's task was to judge, as quickly and as accurately as possible, whether the verb was an action verb (namely, a verb involving a movement of the body). Participants consistently entered a "yes" response with the right click of the mouse, whereas they entered a "no" answer with the left click of the mouse. The nonaction verbs trials were not analyzed; they were included only to develop a task for the participants. 


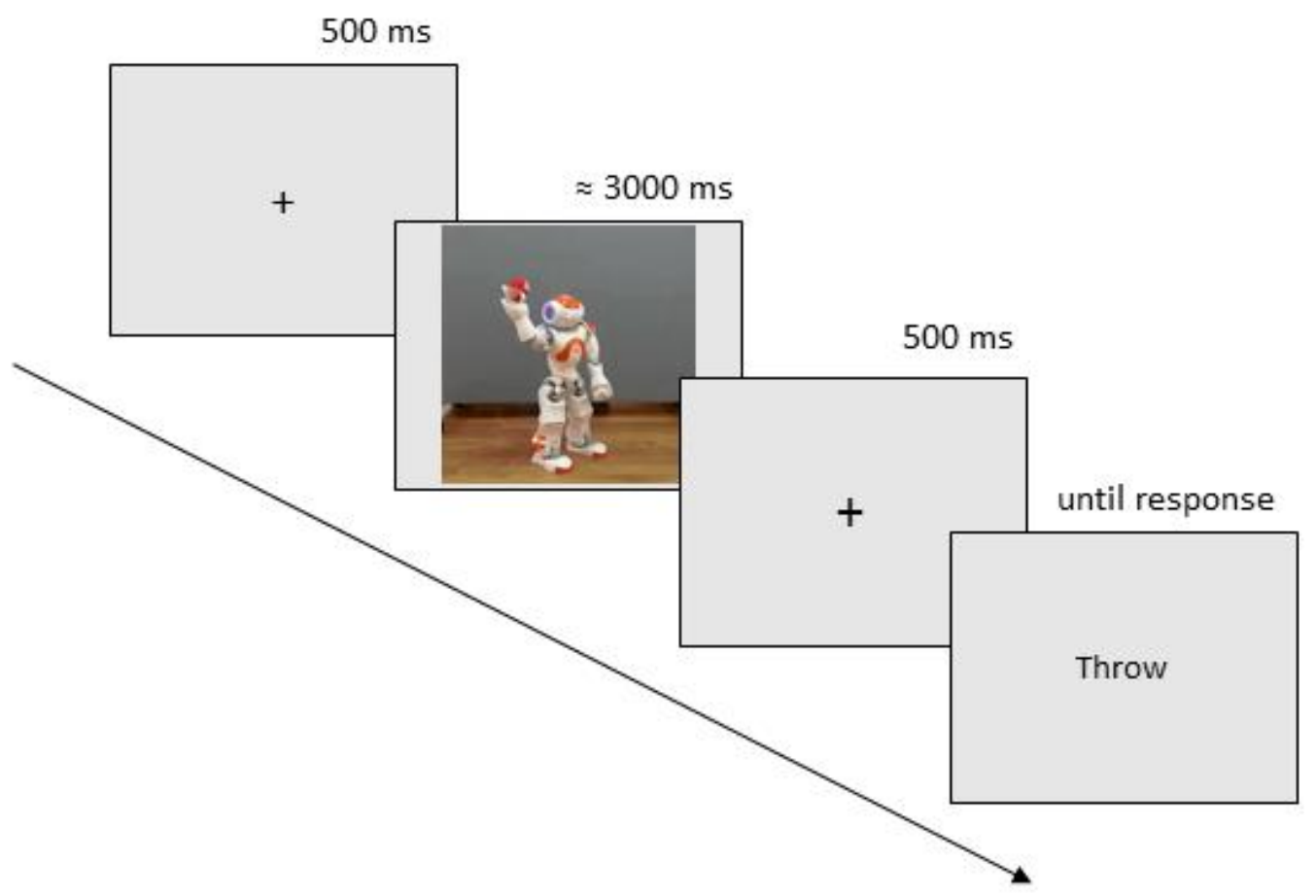

Figure 2: Procedure of the experiment task. The fixation cross, the prime video and the verb stimulus were centered on a uniform gray background. The arrow represents the sequence of one trial.

\subsection{Data analysis}

Participants' response time and accuracy for trials with action verbs were recorded. Only the response times of the correct trials were analyzed ( $97 \%$ of the data) since trials with errors were excluded of the analyses. We used the lmer function of the lme 4 package (Bates, Mächler, Bolker, \& Walker, 2014) in R environment (R version 3.3.0, R Core Team (C 2016) to build linear mixed-effects models. Participants and words items were specified as randomeffects factors. Two fixed-effects factors were included: the congruency of the verb (congruent verb $\mathrm{x}$ incongruent verb) and the type of agent (human $\mathrm{x}$ robot) as well as their interaction. The $p$ values were obtained for $\mathrm{F}$ values (Type III ANOVA) with the error 
degrees of freedom calculation based on Satterhwaite's approximation. The significance level was set at $p<0.05$.

\section{Results}

Response times (see Fig. 3) varied according to the congruency $(\mathrm{F}(1,2110)=89.29 ; p<$ $0.001)$ but not according to the type of agent $(\mathrm{F}(1,2110)=0.04 ; p=0.84)$. There was no significant interaction between the type of agent and the congruency $(F(1,2110)=1.47 ; p=$ 0.22). With the human agent as the prime, the response time for congruent action verbs ( $\mathrm{M}$ $=738.55, \mathrm{SD}=199.35)$ was significantly shorter than that of the incongruent action verbs $(\mathrm{M}$ $=852.06, \mathrm{SD}=249.51 ; p<0.001)$. Similarly, with the robotic agent as the prime, the response time for congruent action verbs $(\mathrm{M}=739.32, \mathrm{SD}=168.25)$ and for incongruent action verbs $(\mathrm{M}=837.11, \mathrm{SD}=241.49)$ were significantly different $(p<0.001)$.

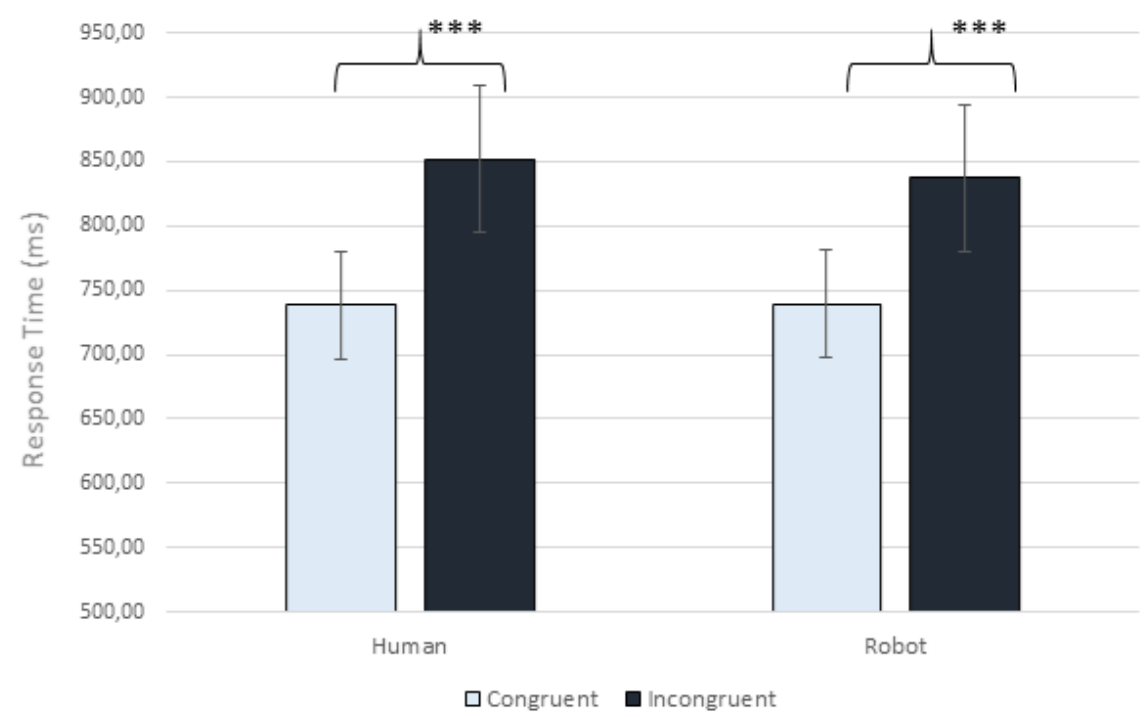

Figure 3. Mean response time of the Japanese participants according to the congruency (congruent, incongruent) and the type of agent (human, robot). The error bars indicate the $95 \%$ confidence interval. $* * *$ significant difference with $p<0.001$ 


\section{Discussion}

The aim of this study was to assess whether the action-language relationship can be modulated according to the agent performing an action. To do so, we compared priming effects obtained in action verb processing when the action presented was performed by a human agent (human) or a non-human agent (robot). Our results confirmed that perceiving a biological action facilitates the subsequent processing of a congruent action verb (Beauprez \& Bidet-Ildei, 2017) since our participants were faster to answer when the action of the prime and the action of the verbs were congruent. However, contrary to our hypothesis, this facilitation effect was also found when perceiving a robot performing an action and could indicate that the humanness of the agent is not a determinant characteristic in the actionlanguage relationship.

Another explanation could be related to the cultural specificities of the Japanese people with regards to their familiarity with and beliefs about robots.

Indeed, Japan has more robots than any other country; so, Japanese people have more exposure to robots in real life/ For example, since 2014, SoftBank (a Japanese telecommunication company) has used the robot Pepper in their store to welcome, support and guide customers in their shopping or to entertain them. Indeed, Japan promotes the use of robots to support human interaction, and robots frequently appear at public events or on television, such as the robot dog Aibo of the Sony company or the humanoid robot Asimo of the Honda company. In a study by MacDorman and colleagues (2007), 731 participants from Japan and the United States completed a questionnaire including a question on their level of familiarity with robots. On average, Japanese female participants had $110 \%$ more robotrelated experiences than US female participants had. Japanese male participants had 69\% more robot-related experiences than US male participants had. 
Moreover, Japanese people are known to be more accepting of robots. Indeed, the original religion of Japan, Shinto, derives from a belief that spirits can inhabit objects (animism), which could lead to a different sort of relationship with robots (MacDorman, Vasudevan, \& Ho, 2009) than that experienced by other cultures. Some authors suggest that the beliefs we have about the minds of others modify how we process sensory information. For example, Wykowska et al. (2014) obtained different results regarding whether the participants thought a robot was controlled by a human mind rather than by a machine. In their first experiment, attentional control over sensory processing was enhanced when participants observed a human compared to a robot. However, in a second experiment, they demonstrated that this sensory gain control was enhanced when participants observed a robot that they thought was control by a human mind compared to when they thought it was control by a machine. Thus, the mental states we attribute to robots modify the way we behave with them (see also Hofer, Hauf, \& Aschersleben, 2005, for evidence with children).

Therefore, we speculate that these cultural specificities of Japanese participants concerning robots may change their capacity to activate their own motor repertoire when perceiving robots acting. Thus, we carried out a second experiment to assess this hypothesis.

\section{Experiment 2}

The aim of this experiment was to determine whether the effects obtained in Experiment 1 with Japanese people could be related to the cultural specificities of Japanese participants. For this, we decided to reproduce the experiment with French people who are less familiar with robots in their daily life and are less likely to attribute mental states to them. Indeed, according to the European Commission ${ }^{3}$, few European citizens have experience using robots

\footnotetext{
${ }^{3} 2012$ report on «Public attitudes towards robots" http://ec.europa.eu/commfrontoffice/publicopinion/archives/ebs/ebs_382_en.pdf
} 
(less than $15 \%$ have used a robot at home or at work or somewhere else). Moreover, for French people and European people in general, the image of a robot is more related to an instrument-like machine than to a human-like machine, so they interact with robots not as communicative agents but as tools.

The hypothesis was that if the humanness of the agent is not important for the actionlanguage relationship, then we should replicate the results found in Japan. Namely, a facilitation effect on action-verb processing should be obtained after observing either a human or a robot performing a congruent action. In contrast, if it is the familiarity with and/or the beliefs towards robots that explains the results of Experiment 1, the results of the French and Japanese participants should be different. In this case, the facilitation effect on action verb processing should be obtained only after observing a congruent action produced by a human agent.

\section{Method}

\subsection{Participants}

Eighteen French university students participated in this experiment $(\mathrm{M}=19$-year-old, $\mathrm{SD}=$ 2.57; 7 male, 16 right-handed). All participants had normal or corrected-to-normal vision, no history of motor, perceptual or neurological disorders, and French as their mother tongue. Moreover, all participants provided their written informed consent prior to their inclusion in the experiment. They were also unaware of the purpose of the study.

\subsection{Stimuli and procedure}

The procedure of this second experiment was the same as for experiment 1 except that it was conducted with French participants instead of Japanese participants. To adapt the material to 
French people, action verbs were translated to french (see appendix A). All verbs were presented in the infinitive form.

\subsection{Data analysis}

As in experiment 1, participants' response time and accuracy for trials with the action verbs were recorded. Only the response times of the correct trials were analyzed ( $91 \%$ of the data) since trials with errors were excluded of the analyses. Linear mixed-effects models were used with participants and words items specified as random-effects factors. Two fixed-effects factors were included: the congruency of the verb (congruent verb $\mathrm{x}$ incongruent verb) and the type of agent (human $\mathrm{x}$ robot) as well as their interaction. The $p$ values were obtained for $\mathrm{F}$ values (Type III ANOVA) with error degree of freedom calculation based on Satterhwaite's approximation. The significance level was set at $p<0.05$.

\section{Results}

Response time (see Fig. 4) varied according to the congruency $(\mathrm{F}(1,1960)=46.24 ; p<0.001)$ but not according to the type of agent $(\mathrm{F}(1,1960)=2.74 ; p=0.09)$. A significant interaction between the type of agent and the congruency was found $(\mathrm{F}(1,1960)=11.91 ; p<0.001)$. With the human agent, the response time for congruent action verbs $(\mathrm{M}=663.83, \mathrm{SD}=147.99)$ was significantly shorter than that of the incongruent action verbs $(\mathrm{M}=768.36, \mathrm{SD}=163.47$; $p<0.001)$. However, with the robotic agent, response time for congruent action verbs $(\mathrm{M}=$ 685.07, $\mathrm{SD}=174.78)$ and for incongruent action verbs $(\mathrm{M}=715.35, \mathrm{SD}=137.89)$ were not significantly different $(p=0.29)$. 


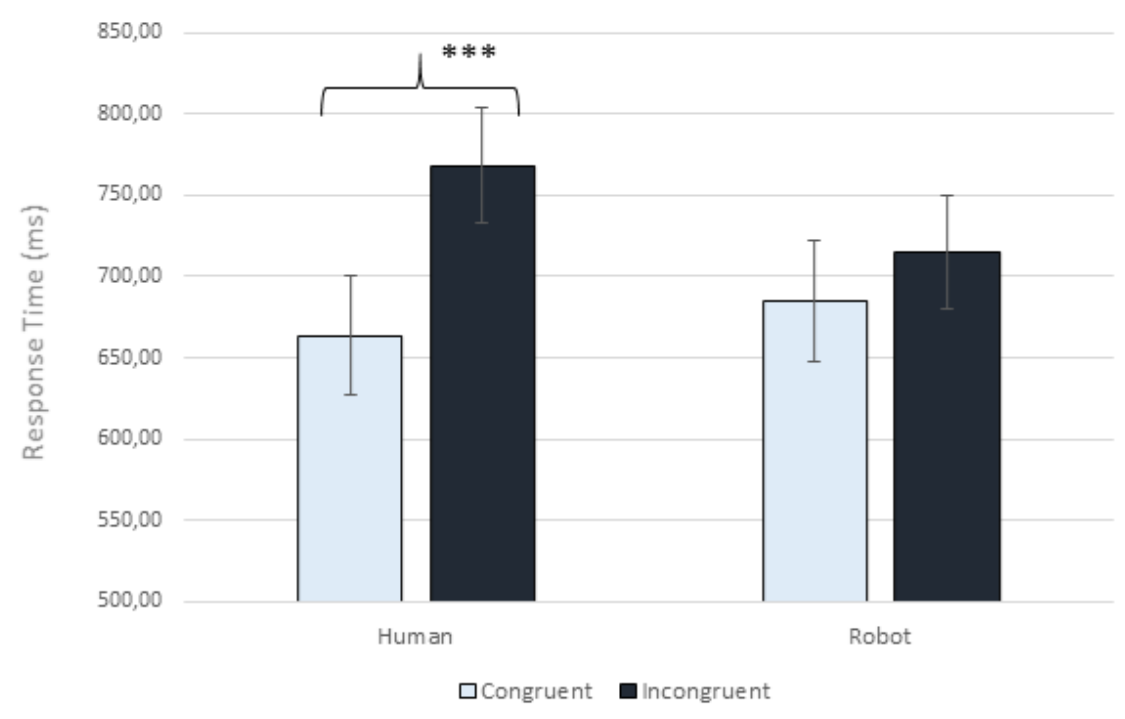

Figure 4. Mean response time of the French participants according to the congruency (congruent, incongruent) and the type of agent (human, robot). The error bars indicate the $95 \%$ confidence interval. $* * *$ significant difference with $p<0.001$

\section{Discussion}

The aim of this second study was to assess whether the absence of differences between the effects obtained with a human and a robotic agent in Experiment 1 could be related to the cultural specificities of Japanese people concerning robots. The results obtained in this second experiment with French participants confirmed again that perceiving a biological action primes the processing of action verbs (Beauprez \& Bidet-Ildei, 2017). Interestingly, we observed here that the priming effect could be due to an interference more than a facilitation effect. Participants are perturbed in the processing of incongruent action verbs in comparison with other conditions. This is surprising because, in the previous literature, when action and action verbs are processed, a facilitation was subsequently and classically observed (Beauprez \& Bidet-Ildei, 2017; Bidet-Ildei et al., 2011). However, given the speed of response times observed in this experiment (approximately $100 \mathrm{~ms}$ less than in Experiment 1), it is possible 
that our participants cannot be accelerated more in the congruent condition, which can account for the absence of a facilitation effect. Importantly, whatever the origins of the priming effect observed when a human agent produces an action, the crucial effect is that it disappears when a robotic agent produces the action, suggesting that the relationship between action and language is dependent on the agent who performs the action.

One possible explanation for this result could be that the French participants, unlike Japanese participants, might have been unable to recognize the action performed by the robot. If robot actions are not recognized (for example, seeing the robot scratching could be understood as dancing), then all of the verbs would be incongruent regarding the prime, explaining the absence of facilitation effect. However, we carried a short questionnaire concerning the recognition of the actions in order to rule out this possibility. After the experimental task, each videos of the task was presented to the participants who were asked to say what action was depicted according to them. The video obtained the score 1 when the answer provided by the participants corresponded to the action (the participants gave the exact verb or a semantically close verb) or obtained the score 0 when the answer differed semantically from the one expected. The percentage obtained allowed us to confirm that the actions of the robot were recognized as well as those of the human (95\% of recognition).

It seems more likely that the absence of the facilitation effect with robots is related to the fact that for French participants seeing a robot may not enable the activation of motor representations, which are the origins of the action-language relationship (e.g., Bidet-Ildei et al., 2011). This would be in accordance with the idea that sensorimotor representations are involved only when the observed action is close to the perceiver's motor repertoire (CalvoMerino et al., 2005; Martel, Bidet-Ildei, \& Coello, 2011). These results also support the idea that the strength of the sensorimotor experiences and the motor repertoire of a person play a role in the processing in action words (Lyons et al., 2010). 
As suggested in the discussion of the first experiment, the absence of motor resonance in French participants could be explained by Japanese participants' familiarity with and perception of robots, two major areas of difference between the two groups. Japanese participants are both more exposed to robots in their daily life and more likely to attribute mental states to them.

Interestingly, some authors have demonstrated an influence of visual familiarity on the activation of action representations. Indeed, Amoruso and Urgesi (2016) showed videos of action performed by humans or dogs to participants familiar with dogs (for example, because they own a dog) or not. The participants familiar with dogs showed a similar level of motor activation when seeing videos displaying actions performed by a human being or by a dog, whereas participants with no familiarity with dogs showed higher motor activation when observing human actions. Following this idea, we can hypothesize that, in our experiment, the relationship between action and language disappeared when the agent was a robot because French participants are not familiar with robotic agents (contrary to Japanese participants), and consequently, they do not activate their motor representations when they observed a robot that produced an action.

We decide to test this assumption in Experiment 3. For this, we propose to assess the link between action and language when French participants are familiarized with robots. If the difference in familiarity with robots is what explains the difference between our results with French and Japanese participants, then we should be able to reproduce the Japanese results in French participants that have been familiarized with robots.

\section{Experiment 3}


The aim of this experiment was to assess the role of visual familiarity in the link between action and language. For this, we decided to reproduce the previous experiments with two groups of French participants: a control group and a group which was familiarized to the Nao robot before completing the experimental task.

\section{Method}

\subsection{Participants}

Forty-four French university students participated in this experiment. Twenty-two were in the control condition ( $\mathrm{M}=19$-year-old, $\mathrm{SD}=1.04 ; 13$ male, 21 right-handed). The other twentytwo were in the familiarization condition $(\mathrm{M}=19$-year-old, $\mathrm{SD}=0.75 ; 15$ male, 19 righthanded). All participants had normal or corrected-to-normal vision, no history of motor, perceptual or neurological disorders, and French as their mother tongue. Moreover, all participants provided their written informed consent prior to their inclusion in the experiment. They were also unaware of the purpose of the study.

\subsection{Stimuli and procedure}

The procedure of this experiment was exactly the same as in experiments 1 and 2 . However, the participants of the familiarization condition went through a familiarization phase. This phase lasted approximately 10 minutes and consisted of text and two short videos about Nao, the robot used during the experiment. The aim of the text and the video was to introduce Nao to accustom our participants to it and to make it seem more human to them. The text was read by the experimenter who explained in which situation Nao is used (education, patient reeducation, etc.) and how it interacts with humans in these situations. One of the two videos was an example of one of these situations (Nao interacting with children with autistic spectrum disorder), and the other video was a small presentation of Nao by itself. The aim of 
this familiarization was to emphasize the interactive side of Nao and to get the participants used to seeing it. After the familiarization phase, the participants received a questionnaire about robots (the "Negative attitude toward robot scale", Nomura, Kanda, \& Suzuki, 2006). Participants from the control condition also received this questionnaire before the experimental task. The aim of this questionnaire was to assess the effectiveness of the familiarization phase. The questionnaire consisted of items concerning attitude towards the interaction with robots, attitude towards the social influence of robots and attitude towards emotions in interactions with robots. Participants answered with a 5 points scale (going from "I strongly disagree" to "I strongly agree"). A mean score based on their response was calculated so that a high score (close to 5) would indicate a negative attitude towards robots while a low score (close to 1) would indicate a positive attitude towards robots.

\subsection{Data analysis}

Participant's response time and accuracy for trials with action verbs were recorded. Only the response times of the correct trials were analyzed (90\% of the data) since trials with errors were excluded of the analyses. Linear mixed-effects models were used with participants and words items specified as random-effects factors. Three fixed-effects factors were included: the congruency of the verb (congruent verb $\mathrm{x}$ incongruent verb), the type of agent (human $\mathrm{x}$ robot) and the group (control $\mathrm{x}$ familiarized) as well as their interaction. The $p$ values were obtained for F values (Type III ANOVA) with error degree of freedom calculation based on Satterhwaite's approximation. The significance level was set at $p<0.05$.

\section{Results}

The results showed a significant interaction between the type of agent, the congruency of the verbs and the group $(\mathrm{F}(1,4722)=4.714 ; p=0.03)$. 
More precisely, for the control condition (see Fig. 5), with the human agent, the response time for congruent action verbs $(\mathrm{M}=673.19, \mathrm{SD}=128.49)$ was significantly shorter than that for the incongruent action verbs $(\mathrm{M}=759.90, \mathrm{SD}=133.79 ; p<0.001)$. However, with the robotic agent, the response time for congruent action verbs $(\mathrm{M}=726.63, \mathrm{SD}=$ 128.50) and for incongruent action verbs $(\mathrm{M}=735.04, \mathrm{SD}=125.71)$ were not significantly different $(p=0.27)$.

For the familiarization condition, with the human agent, the response time for the congruent action verbs $(\mathrm{M}=658.59, \mathrm{SD}=122.99)$ was significantly shorter than that for the incongruent action verbs $(\mathrm{M}=733.12, \mathrm{SD}=127.33 ; p<0.001)$. Similarly, with the robotic agent, response time for congruent action verbs $(M=676.21, S D=137.73)$ was significantly shorter than that for the incongruent action verbs $(\mathrm{M}=733.39, \mathrm{SD}=135.91 ; p<0.001)$.

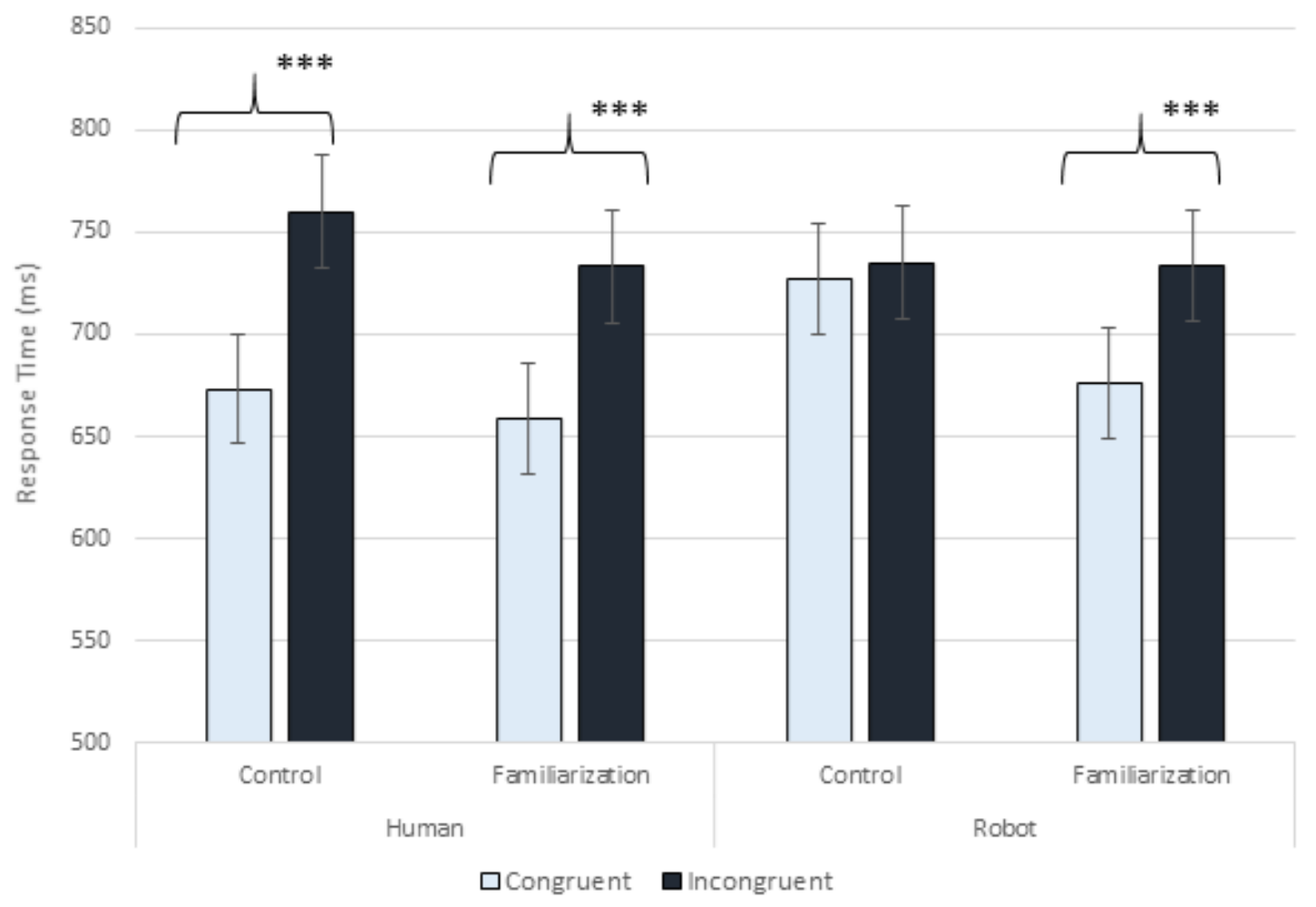


Figure 5. Mean response time of the French participants according to the congruency (congruent, incongruent) and the type of agent (human, robot). The error bars indicate the $95 \%$ confidence interval. $* * *$ significant difference with $p<0.001$

Concerning the attitude questionnaire, the score of the familiarized group (2.81) was slightly lower than the score of the control group (3.08), which indicates a trend of a more positive attitude toward robots in this group. However, the Student's t test revealed that this difference was not significant $(p=0.09)$.

\section{Discussion}

The aim of this third study was to assess whether the difference between our Japanese and French participants could be related to their familiarity with robots. If our hypothesis was true, familiarizing French participants should have enabled us to obtain the same results as those of Japanese participants. The results obtained in this third study were in agreement with this hypothesis. Indeed, while French participants who were not familiarized with robots produced different results when observing a robot and a human being (as in experiment 2), French participants who were familiarized with robots produced results similar to those of Japanese participants. Thus, when familiarized participants perceived an action by either a human agent or a robot agent, it led to facilitation (as in experiment 1).

It is worth noting that this effect occurred even though the familiarization was not enough to significantly modify the attitudes of our participants towards robots. This could indicate that the influence of observing a robot relies more on visual experience and that a participant's attitude does not interfere with this action-language relationship. However, it is important to remember that the attitude of our participants toward robots was neither high nor low but rather indifferent. Therefore, we cannot exclude that in another situation attitude 
might play a role in the action-language relationship. In fact, we could expect it to interfere when people have a truly negative attitude toward the agent performing an action. For example, Gutsell and Inzlicht (2010) demonstrated that a person is less likely to resonate with another person when this person belongs to a disliked group: the suppression of the mu rhythm was indeed linked to the amount of prejudice toward this group.

The results of the present study cannot be explained in terms of attitude towards the agent. Thus, rather than the explicit attitude, it is the visual experience that seems to have impacted the influence of robot observation on language processes (see Fig. 6 for a schematic representation of this interpretation). We suggest that this visual experience may have a more implicit influence by modulating our sensorimotor representations.

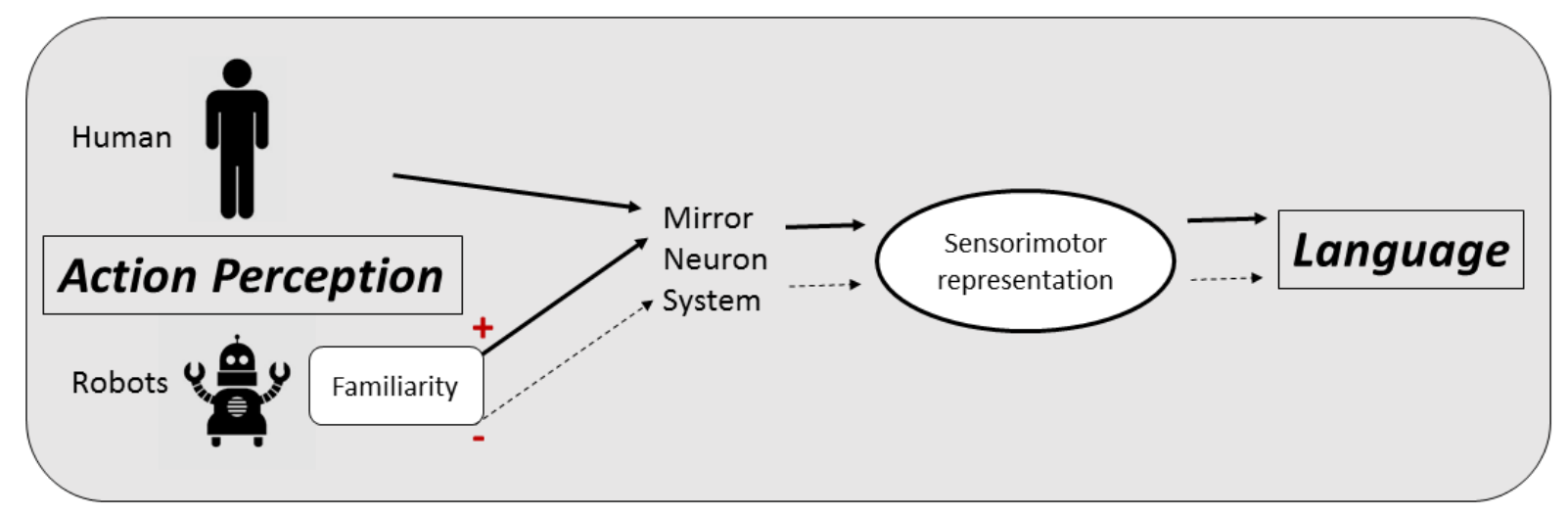

Figure 6. Schematic representation of the influence of familiarity on the actionlanguage relationship. Solid lines represent an activation, and dashed lines represent less or no activation. Perceiving a robotic action would activate the representation of this action when the participant is familiar with robots.

\section{General Discussion}

Previous studies have demonstrated that the influence of the perception of an action on the subsequent processing of language (Beauprez \& Bidet-Ildei, 2017; Liepelt et al., 2012) and 
that this influence is not mandatory but rather depends on some properties of the observed action (Beauprez et al., 2018, Beaupez \& Bidet-Ildei, 2018). Here, we studied the role of the humanness of the agent performing an action. Different results were obtained according to the nationality of our participants. In France (experiment 2 and control group of experiment 3), the results seemed to indicate that the humanness of the agent is a crucial property of the action since when it is modified the action-language relationship is not found. This would be in agreement with previous studies that have suggested that perceiving a robot does not produce mirror neuron activation (Matsuda et al., 2015; Tai et al., 2004), which is required to support the motor resonance. In contrast, in Japan (experiment 1) the results seemed to indicate that observing an agent that is human is not so crucial because when the humanness of the agent is modified the action-language relationship is still present. This aligns with the other studies that have suggested that we are able to activate the mirror neuron system when observing a robot (Gazzola et al., 2007a; Oberman et al., 2007; Press et al., 2005).

We could wonder what in particular disturbed our French participants when observing a robot. It is worth noting that robots differ from human beings in two important aspects: their appearance and their kinematics. In addition, it has been demonstrated that both the kinematics (Bidet-Ildei, Méary, \& Orliaguet, 2006; Pavlova, Krägeloh-Mann, Birbaumer, \& Sokolov, 2002) and the appearance (Chaminade, Hodgins, \& Kawato, 2007) are important in the perception of biological motion and for motor resonance. For example, it has been demonstrated that the observation of similar faces (same race) leads to stronger motor resonance than that of dissimilar faces (Liew, Han, \& Aziz-Zadeh, 2011). Similarly, it has been shown that modifying kinematics of action perturbs the capacity to anticipate the following component of a motor sequence (Kandel, Orliaguet, \& Viviani, 2000). For example, Bisio et al. (2014) showed motor contagion (the observer's motor performance might automatically replicate some features of the observed agent) when their participants were 
observing robots whose kinematics respected the biological law of motion, whereas no motor contagion was obtained when participants observed robots performing movements with nonbiological kinematics.

Our study does not allow differentiation of the influence of the kinematics from the influence of the appearance since Nao has both an appearance dissimilar to human beings and modified kinematics. However, even if Nao's kinematics differ from that of humans, it is worth noting that Nao's design is highly motivated by the way humans move. In their study, Kupferber and her colleagues (2012) demonstrated that morphological similarities (i.e., those concerning the structure of an organism) between agent and observer are important. More precisely, the joint configuration of an individual influences the way he moves (i.e., motility). The same industrial robot arm performing the same movements induced motor interference when it had human-like motility (quasi-biological movement), but not when it was shown in a standard industrial configuration (non-biological movement). Moreover, it has been demonstrated that the kinematics of robotic actions have no influence on motor resonance when observers are highly familiar with the goal of an action (Gazzola et al., 2007a). Because Nao has some morphological similarity with humans (quasi-biological movement) and only performed usual actions in our experiments, we think that the kinematic explanation can be ruled out to interpret our results.

As touched upon earlier, a more probable interpretation of the difference between the French and Japanese participants may be the difference in familiarity that they have with robots. Perhaps the motor system is flexible and not strictly limited to our sensorimotor experiences. More precisely, familiarity would enable resonance even when observing nonhuman actions (see for example Amoruso and Urgesi 2016). Similarly, in an fMRI study, participants familiarized with certain dance sequences (observational learning) showed similar cerebral activity in premotor and parietal regions as trained participants (physical learning) 
when watching these sequences (Cross, Kraemer, Hamilton, Kelley, \& Grafton, 2009). Following the same logic, our results suggest that the influence of action observation on language processing is related to the activation of the sensorimotor representation which depends not only on our motor experiences but also on our visual experiences. The results of experiment 3 (familiarized group) are in agreement with these results. Indeed, after visual familiarization, the same influence of action observation on language processing was obtained for robot agent and human agent.

As explained before, in addition to familiarity with robots, there is another difference between French and Japanese participants related to the way they could conceive robots. Indeed, Japanese are not only more familiar seeing robots in their daily lives, but they are also more used to interacting with them; thus, they may more easily consider them as potential partners for interaction than the French would. Indeed, studies have suggested that to consider robots as communicative agents infants need to see them interacting with human (Arita, Hiraki, Kanda, \& Ishiguro, 2005) and that the believed humanness of a robot is important for humans to corepresent actions (Stenzel et al., 2012), and so, it is important in human-robot interactions. Moreover, robots are more socially accepted by Japanese citizens than by European citizens. For example, Nomura, Syrdal and Dautenhahn (2015), showed that UK people felt more negatively towards humanoid robots than did Japanese people. It is worth noting that despite this particularity of the Japanese people, some studies did not report mirror neuron system activity in Japanese participants when watching robots performing actions (Matsuda, Hiraki, \& Ishiguro, 2015). A difference between our study and the one by Matsuda, Hiraki and Ishiguro is the robot used. In their robot condition, Repliee Q2 without its silicone skin was used. The appearances of Repliee Q2 and the robot we used in our study, Nao, are very different. In contrast to Repliee Q2, which seems less attractive, Nao has a cute appearance. Indeed, Nao was designed to make people want to interact with it; it is small, 
colorful and possesses pleasantly rounded features. Maybe it is easier to attribute humanness to Nao than to other robots. Thus, it could be interesting in the future to replicate our results with different types of robots.

Anyway, in Experiment 3, the results of the attitude questionnaire revealed that familiarization was not enough to change the attitude of our participants. This result is not surprising given that the familiarization phase only lasted 10 minutes; this is certainly not enough time to modify individuals' beliefs. Thus, this result seems to indicate that, in our experiment, only visual familiarity with the robot was modified during the familiarization. This familiarity would be enough to enable our participants to activate their sensorimotor representation, even when an observed action differs from their motor experience. In other words, if observers are familiar with an agent, any differences can be ignored.

Thus, it seems that increasing the interaction between people and robots would increase familiarity with robots, which would be key to being able to resonate with robots and recreate an action-language relationship. In any case, our results indicate that the nature of the agent is an important property of an action in order to produce semantic activation during word processing. However, we also demonstrated that this property is not essential. In contrast, we can see that if observers are familiar with robots, the modification of this property can be ignored. In this case, action-verb processing can be facilitated when observing actions performed by human as well as robotic agents. This supports the idea that the motor repertoire is flexible and can bridge differences in embodiment. In agreement, brain imagery data showed that the mirror neuron system can be activated even when watching familiar actions that are not part of our motor repertoire. For example, Gazzola and her colleagues (2007b) showed that aplasics subjects (born without hands) activate their mirror neuron system as strongly as typically developed adults when viewing hand actions. Overall, the results of the present studies confirm the flexibility of the activation of sensorimotor 
representation and extend previous findings by demonstrating that observing an action facilitates language processing not only when perceiving a human agent but also when perceiving a non-human agent, such as a robot that we are familiar with. Moreover, the main finding of this study is to demonstrate the plasticity of the action-language relationship. Thus, our results demonstrate that the activation of the sensorimotor representation is sensitive to prior experience. Additionally, our results indicate that the update of these sensorimotor representations is rapid. In a recent experiment, Bidet-Ildei and her colleagues (2017) demonstrated the quick update of sensorimotor representation and showed that $24 \mathrm{~h}$ of sensorimotor deprivation is enough to affect action verb processing. We now demonstrate that a short period of familiarization (10 minutes) is enough to modify these representations, making their activation more flexible.

Thus, to answer the question in our title: one's language could certainly be influenced when watching C-3PO moving, but only if he or she has seen at least 10 minutes of one of the Star Wars movies!

\section{Conclusion}

In conclusion, as robots are becoming more integrated in everyday life, it is becoming increasingly necessary to understand how the perception of robots influences our cognitive functions. Thus, the data presented here must be taken into consideration in order to improve the human-robot interaction. In particular, the use of robots is now being considered in education and in therapy. Indeed, as robots have predictable behavior and simple conversational functions, they might be adapted to speech-language therapy for people with language disorders or with more specific populations. For example, the French association "Autistes sans frontières" has tested Nao as a remediation tool for children with autism spectrum disorder to enhance their communication as well as their speaking and listening 
skills. The results of our studies are encouraging since they indicate that the observation of robots can influence language processing and that familiarizing people could be the key to optimize this kind of therapy. However, before reaching that point, numerous questions still need to be addressed. As a first step, the objective of future research could be to assess the action-language relationship in populations with autism spectrum disorder to determine whether this relationship is (1) expressed the same way and (2) influenced the same way as with a typical population.

\section{Acknowledgements}

This work was supported by the Japan Society for the Promotion of Science. Experiment 1 was conducted during an in-doc by Sophie-Anne Beauprez at the University of Tokyo.

We would like to thank Yoshida Fumiaki and Masaoka Shiori for their help in the experiment development, the recruitment of the participants and data collection.

Ethical approval: The experiments were conducted in accordance with the ethical standards of the institutional and with the 1964 Helsinki declaration. 


\section{Appendix A: Prime video and list of verbs}

\begin{tabular}{|c|c|c|c|}
\hline \multirow{2}{*}{$\begin{array}{l}\text { Actions of the videos } \\
\text { (English translation / } \\
\text { French / Japanese) }\end{array}$} & \multicolumn{2}{|c|}{ Action Verbs } & \multirow{2}{*}{ Non-Action Verbs } \\
\hline & Congruent & Incongruent & \\
\hline $\begin{array}{c}\text { Acquiesce } \\
\text { Acquiescer / うなずく }\end{array}$ & Acquiesce & Read & Want \\
\hline $\begin{array}{c}\text { Applaud } \\
\text { Applaudir } / た た く\end{array}$ & Applaud & Move back & Dream \\
\hline $\begin{array}{c}\text { Clean } \\
\text { Nettoyer / ふく }\end{array}$ & Clean & Take & Wish \\
\hline $\begin{array}{c}\text { Deny } \\
\text { Nier /くびをふる }\end{array}$ & Deny & Throw (a ball) & Recognize \\
\hline $\begin{array}{c}\text { Kneel } \\
\text { S'agenouiller / しゃがむ }\end{array}$ & Kneel & Scratch & Hope \\
\hline $\begin{array}{c}\text { Move Back } \\
\text { Reculer/さがる }\end{array}$ & Move back & Turn & Envy \\
\hline $\begin{array}{c}\text { Read } \\
\text { Lire/みる }\end{array}$ & Read & Deny & Progress \\
\hline $\begin{array}{c}\text { Reverence } \\
\text { S'incliner/おじぎする }\end{array}$ & Reverence & Throw (in a bin) & Believe \\
\hline $\begin{array}{c}\text { Salute } \\
\text { Saluer/てをふる }\end{array}$ & Salute & Stand up & Cost \\
\hline $\begin{array}{c}\text { Scratch } \\
\text { Gratter / かく }\end{array}$ & Scratch & Salute & Understand \\
\hline $\begin{array}{c}\text { Show } \\
\text { Montrer / ゆびさす }\end{array}$ & Show & Acquiesce & Guess \\
\hline $\begin{array}{c}\text { Stand Up } \\
\text { Se lever / たつ }\end{array}$ & Stand up & Show & Choose \\
\hline $\begin{array}{c}\text { Take } \\
\text { Prendre / とる }\end{array}$ & Take & Kneel & Doubt \\
\hline $\begin{array}{c}\text { Throw (in the bin) } \\
\text { Jeter / すてる }\end{array}$ & Throw & Clean & Consider \\
\hline $\begin{array}{c}\text { Throw (a ball) } \\
\text { Lancer / なげる }\end{array}$ & Throw & Reverence & Think \\
\hline $\begin{array}{c}\text { Turn } \\
\text { Tourner / まわる }\end{array}$ & Turn & Applaud & Have \\
\hline
\end{tabular}




\section{Appendix B: examples of frames, "cleaning" action performed by the robotic and the human agent}
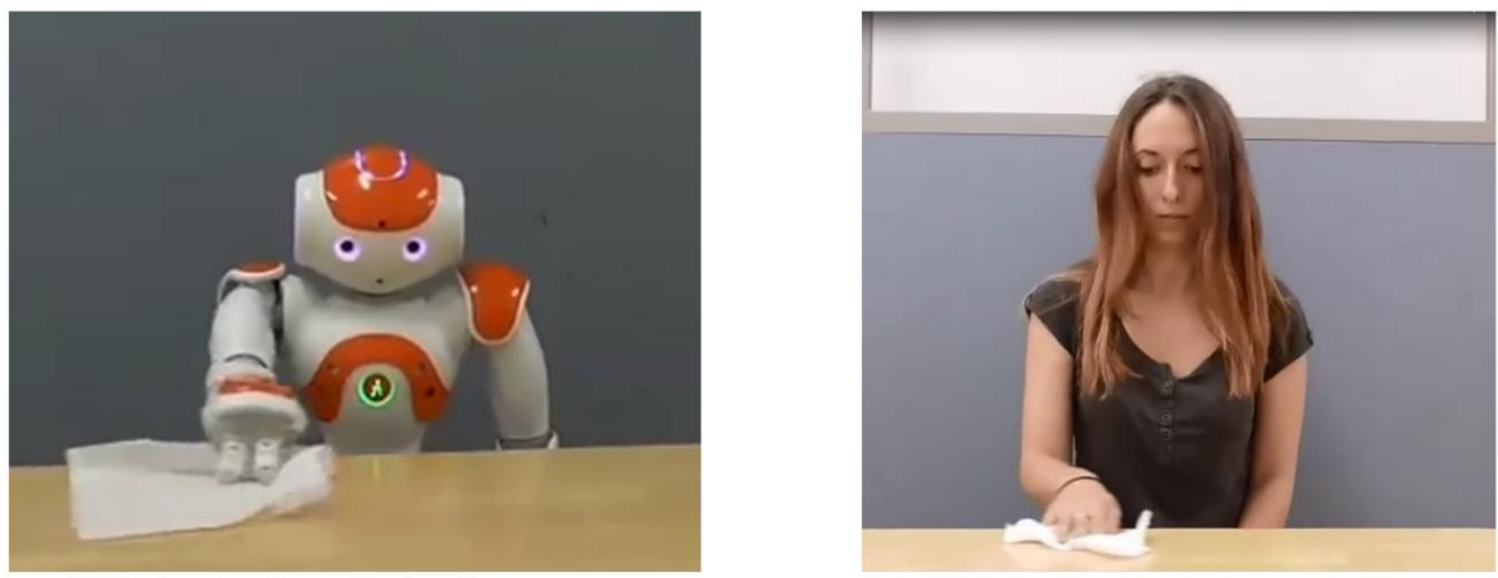

\section{References}

Amoruso, L., \& Urgesi, C. (2016). Familiarity modulates motor activation while other species' actions are observed: a magnetic stimulation study. European Journal of Neuroscience, 43(6), 765-772. https://doi:10.1111/ejn.13154

Anelli, F., Borghi, A.M., \& Nicoletti, R. (2014). Grasping the pain: Motor resonance with dangerous affordances. Consciousness and Cognition, 21(4), 1627-1639. https://doi.org/10.1016/j.concog.2012.09.001

Aravena, P., Delevoye-Turrell, Y., Deprez, V., Cheylus, A., Paulignan, Y., Frak, V., \& Nazir, T. (2012). Grip force reveals the context sensitivity of language-induced motor activity during «action words » processing: evidence from sentential negation. PLoS ONE, 7(12), e50287. https://doi.org/10.1371/journal.pone.0050287

Arita, A., Hiraki, K., Kanda, T., \& Ishiguro, H. (2005). Can we talk to robots? Ten-month-old infants expected interactive humanoid robots to be talked to by persons. Cognition, 95(3), B49-B57. https://doi.org/10.1016/j.cognition.2004.08.001 
Aziz-Zadeh, L., \& Damasio, A. (2008). Embodied semantics for actions: Findings from functional brain imaging. Journal of Physiology-Paris, 102(1), 35-39. https://doi.org/10.1016/j.jphysparis.2008.03.012

Aziz-Zadeh, L., Wilson, S. M., Rizzolatti, G., \& Iacoboni, M. (2006). Congruent embodied representations for visually presented actions and linguistic phrases describing actions. Current Biology, 16(18), 1818-1823. https://doi.org/10.1016/j.cub.2006.07.060

Bates, D., Mächler, M., Bolker, B., \& Walker, S. (2014). Fitting Linear Mixed-Effects Models using lme4. Journal of Statistical Software, $67(1), \quad 1 \quad$ - 48. http://dx.doi.org/10.18637/jss.v067.i01

Beauprez, S.-A., \& Bidet-Ildei, C. (2017). Perceiving a Biological Human Movement Facilitates Action Verb Processing. Current Psychology, 1-5. https://doi.org/10.1007/s12144-017-9694-5

Beauprez, S.-A., \& Bidet-Ildei, C. (2018). The kinematics but not the orientation of an action influences language processing. Journal of Experimental Psychology: Human Perception and Performance, 44(11), 1712-1726. http://dx/doi.org/10.1037/xhp0000568

Beauprez, S.-A., Toussaint, L., \& Bidet-Ildei, C. (2018). When context modulates the influence of action observation on language processing. PLoS ONE, 13(8), 1-12. https://doi.org/10.1371/journal.pone.0201966

Bidet-Ildei, C., Méary, D., \& Orliaguet, J.-P. (2006). Visual Perception of Elliptic movements in 7to-11-year-old children : Influence of Motor Rules. Current Psychology Letters. Behaviour, Brain \& Cognition, 19(2), 1-10.

Bidet-Ildei, C., Meugnot, A., Beauprez, S.-A., Gimenes, M., \& Toussaint, L. (2017). Short-Term Upper Limb Immobilization Affects Action-Word Understanding. Journal of Experimental Psychology. Learning, Memory, and Cognition, 43(7), 1129-1139. https://doi.org/10.1037/xlm0000373 
Bidet-Ildei, C., Sparrow, L., \& Coello, Y. (2011). Reading action word affects the visual perception of biological motion. Acta Psychologica, 137(3), 330-334. https://doi.org/10.1016/j.actpsy.2011.04.001

Bisio, A., Sciutti, A., Nori, F., Metta, G., Fadiga, L, et al. (2014). Motor Contagion during Human-Human and Human-Robot Interaction. PLoS ONE, 9(8), e106172. https://doi.org/10.1371/journal.pone.0106172

Boulenger, V., Roy, A. C., Paulignan, Y., Deprez, V., Jeannerod, M., \& Nazir, T. A. (2006). Cross-talk between language processes and overt motor behavior in the first $200 \mathrm{msec}$ of processing. Journal of Cognitive Neuroscience, 18(10), 1607-1615. https://doi.org/10.1162/jocn.2006.18.10.1607

Calvo-Merino, B., Glaser, D. E., Grèzes, J., Passingham, R. E., \& Haggard, P. (2005). Action observation and acquired motor skills: an FMRI study with expert dancers. Cerebral Cortex, 15(8), 1243-1249. https://doi.org/10.1093/cercor/bhi007

Chaminade, T., \& Cheng, G. (2009). Social cognitive neuroscience and humanoid robotics. Journal of Physiology-Paris, 286-295. https://doi.org/10.1016/j.jphysparis.2009.08.011

Chaminade, T., Hodgins, J., \& Kawato, M. (2007). Anthropomorphism influences perception of computer-animated characters' actions. Social Cognitive and Affective Neuroscience, 2(3), 206. https://doi.org/10.1093/scan/nsm017

Cross, E. S., Kraemer, D. J. M., Hamilton, A. F. de C., Kelley, W. M., \& Grafton, S. T. (2009). Sensitivity of the action observation network to physical and observational learning. Cerebral Cortex, 19(2), 315-326. https://doi.org/10.1093/cercor/bhn083

Faul, F., Erdfelder, E., Lang, A.-G., \& Buchner, A. (2007). G*Power 3: a flexible statistical power analysis program for the social, behavioral, and biomedical sciences. Behavior Research Methods, 39(2), 175-191. 
Gazzola, V., Rizzolatti, G., Wicker, B., \& Keysers, C. (2007a). The anthropomorphic brain: The mirror neuron system responds to human and robotic actions. NeuroImage, 35(4), 1674-1684.

Gazzola, V., Worp, H. van der, Mulder, T., Wicker, B., Rizzolatti, G., \& Keysers, C. (2007b). Aplasics Born without Hands Mirror the Goal of Hand Actions with Their Feet. Current Biology, 17(14), 1235-1240. https://doi.org/10.1016/j.cub.2007.06.045

Glenberg, A. M., \& Kaschak, M. P. (2002). Grounding language in action. Psychonomic bulletin \& review, 9(3), 558-565. https://doi.org/10.3758/BF03196313

Gutsell, J., \& Inzlicht, M. (2010). Empathy constrained: Prejudice predicts reduced mental simulation of actions during observation of outgroups. Journal of Experimental Social Psychology, 46(5), 841-845. https://doi.org/10.1016/j.jesp.2010.03.011

Hauk, O., Johnsrude, I., \& Pulvermüller, F. (2004). Somatotopic representation of action words in human motor and premotor cortex. Neuron, 41(2), 301-307. https://doi.org/10.1016/S08966273(03)00838-9

Hofer, T., Hauf, P., \& Aschersleben, G. (2005). Infant's perception of goal-directed actions performed by a mechanical device. Infant Behavior and Development, 28(4), 1-11. https://doi.org/10.1016/j.cognition.2011.05.012

Iacoboni, M., Molnar-Szakacs, I., Gallese, V., Buccino, G., Mazziotta, J. C., \& Rizzolatti, G. (2005). Grasping the intentions of others with one's own mirror neuron system. PLoS Biology, 3(3), e79. https://doi.org/10.1371/journal.pbio.0030079

Kandel, S., Orliaguet, J. P., \& Viviani, P. (2000). Perceptual anticipation in handwriting: the role of implicit motor competence. Perception \& Psychophysics, 62(4), 706-716. https://doi.org/10.3758/BF03206917

Kilner, J.M., Paulignan, Y., \& Blakemore, S.J. (2003). An interference effect of observed biological movement on action. Current Biology, 13(6), 522-525. 
Klepp, A., Weissler, H., Niccolai, V., Terhalle, A., Geisler, H., Schnitzler, A., \& Biermann-Ruben, K. (2014). Neuromagnetic hand and foot motor sources recruited during action verb processing. Brain and Language, 128(1), 41-52. https://doi.org/10.1016/j.bandl.2013.12.001

Kuipers, J.-R., van Koningsbruggen, M., \& Thierry, G. (2013). Semantic priming in the motor cortex: evidence from combined repetitive transcranial magnetic stimulation and event-related potential. Neuroreport, 24(12), 646-651. https://doi.org/10.1097/WNR.0b013e3283631467

Liepelt, R., Dolk, T., \& Prinz, W. (2012). Bidirectional semantic interference between action and speech. Psychological Research, 76(4), 446-455. https://doi.org/10.1007/s00426-011-0390-z

Liew, S.-L., Han, S., \& Aziz-Zadeh, L. (2011). Familiarity modulates mirror neuron and mentalizing regions during intention understanding. Human Brain Mapping, 32(11), 1986-97. https://doi.org/10.1002/hbm.21164

Lindemann, O., Stenneken, P., van Schie, H. T., \& Bekkering, H. (2006). Semantic activation in action planning. Journal of Experimental Psychology. Human Perception and Performance, 32(3), 633-643. https://doi.org/10.1037/0096-1523.32.3.633

Lyons, I. M., Mattarella-Micke, A., Cieslak, M., Nusbaum, H. C., Small, S. L., \& Beilock, S. L. (2010). The role of personal experience in the neural processing of action-related language. Brain and Language, 112(3), 214-222. https://doi.org/10.1016/j.bandl.2009.05.006

MacDorman, K. F., Vasudevan, S. K., \& Ho, C.-C. (2009). Does Japan really have robot mania? Comparing attitudes by implicit and explicit measures. AI \& SOCIETY, 23(4), 485-510. https://doi.org/10.1007/s00146-008-0181-2

Martel, L., Bidet-Ildei, C., \& Coello, Y. (2011). Anticipating the terminal position of an observed action: Effect of kinematic, structural, and identity information. Visual Cognition, 19(6), 785-798. https://doi.org/10.1080/13506285.2011.587847 
Matsuda, G., Hiraki, K., \& Ishiguro, H. (2015). EEG-Based Mu Rhythm Suppression to Measure the Effects of Appearance and Motion on Perceived Human Likeness of a Robot. Journal of Human-Robot Interaction, 5(1), 68-81. https://doi.org/10.5898/10.5898/JHRI.5.1.Matsuda

Mollo, G., Pulvermüller, F., \& Hauk, O. (2016). Movement priming of EEG/MEG brain responses for action-words characterizes the link between language and action. Cortex, 74, 262-276. https://doi.org/10.1016/j.cortex.2015.10.021

Nomura, T., Kanda, T., \& Suzuki, T. (2006). Experimental investigation into influence of negative attitudes toward robots on human-robot interaction. AI \& SOCIETY, 20(2), 138-150. https://doi.org/10.1007/s00146-005-0012-7

Nomura, T. T., Syrdal, D. S., \& Dautenhahn, K. (2015). Differences on social acceptance of humanoid robots between Japan and the UK. Procs 4th Int Symposium on New Frontiers in Human-Robot Interaction. The Society for the Study of Artificial Intelligence and the Simulation of Behaviour (AISB), pp. 115-120, 4th Int Symposium on New Frontiers in Human-Robot Interaction, Canterbury, United Kingdom.

Oberman, L., McCleery, J., Ramachandran, V., \& Pineda, J. (2007). EEG evidence for mirror neuron activity during the observation of human and robot actions: Toward an analysis of the human qualities of interactive robots. Neurocomputing, 70(13-15), 2194-2203. https://doi.org/10.1016/j.neucom.2006.02.024

Pavlova, M. A., Krägeloh-Mann, I., Birbaumer, N., \& Sokolov, A. (2002). Biological motion shown backwards: the apparent-facing effect. Perception, 31(4), 435-443. https://doi.org/10.1068/p3262

Press, C., Bird, G., Flach, R., \& Heyes, C. (2005). Robotic movement elicits automatic imitation. Cognitive Brain Research, 25(3), 632-640. https://doi.org/10.1016/j.cogbrainres.2005.08.020 
Press, C., Gillmeister, H., \& Heyes, C. (2006). Bottom-up, not top-down, modulation of imitation by human and robotic models. European Journal of Neuroscience, 24(8), 2415-2419. https://doi.org/10.1111/j.1460-9568.2006.05115.x

Pulvermüller, F. (2005). Brain mechanisms linking language and action. Nature Reviews. Neuroscience, 6(7), 576-582. https://doi.org/10.1038/nrn1706

Ranzini, M., Borghi, A.M., \& Nicoletti, R. (2011). With hands I do not centre! Action- and objectrelated effects of hand-cueing in the line bisection. Neuropsychologia, 49(10). https://10.1016/j.neuropsychologia.2011.06.019

Rizzolatti, G., \& Craighero, L. (2004). The mirror-neuron system. Annual Review of Neuroscience, 27, 169-192. https://doi.org/10.1146/annurev.neuro.27.070203.144230

Rizzolatti, G., Fogassi, L., \& Gallese, V. (2001). Neurophysiological mechanisms underlying the understanding and imitation of action. Nature Reviews. Neuroscience, 2(9), 661-670. https://doi.org/10.1038/35090060

Tai, Y., Scherfler, C., Brooks, D., Sawamoto, N., \& Castiello, U. (2004). The Human Premotor Cortex Is «Mirror» Only for Biological Actions. Current Biology, 14(2), 117-120. https://doi.org/10.1016/j.cub.2004.01.005

Wykowska, A., Wiese, E., Prosser, A., \& Müller, H.J. (2014). Beliefs about the Minds of Others Influence How We Process Sensory Information. PLoS ONE, 9(4), e94339. https://doi.org/10.1371/journal.pone.0094339

Zwaan, R. A., \& Taylor, L. J. (2006). Seeing, acting, understanding: motor resonance in language comprehension. Journal of Experimental Psychology. General, 135(1), 1-11. https://doi.org/10.1037/0096-3445.135.1.1 